\title{
HOW SEEING IS DIFFERENT FROM LOOKING A COGNITIVE PERSPECTIVE ON VERB-PARTICLE CONSTRUCTIONS WITH LOOK AND SEE
}

\author{
Svetlana Nedelcheva ${ }^{1}$
}

\begin{abstract}
In Cognitive linguistics verb-particle (VP) constructions are treated as compositional and analyzable. The particles when combined with the verbs contribute to the overall meaning in the form of image schemas. This article compares the verbparticle constructions with look and see. It aims at analyzing the nuances of meaning of two synonymous verbs that combine with spatial particles and examines the image schemas associated with them.

When the corresponding image schemas are activated they influence the VP constructions, thus they bring forth new evidence for the embodied nature of language and thought. This study also uses the theoretical framework of Construction Grammar to focus on the different ways of processing spatial and non-spatial VP constructions.
\end{abstract}

Key words: cognitive approach, verb-particle constructions, image schemas, see, look

\section{Introduction}

Achievements in the field of cognitive linguistics over the last 35 years have revealed that the meanings of verb-particle (VP) constructions ${ }^{2}$ are conceptually related to each other, and various studies have shown that foreign learners can benefit from utilizing these approaches. However, the insights in research have not reached ELT classrooms and the way idiomatic meanings of phrasal verbs are taught. Although the Internet abounds in available resources, there is a striking disconnection to the most relevant theories that have become leading in this field of study and foreign-language textbooks are predominantly based on outdated teaching theories.

Teachers are generally left with two ways of phrasal verb organization semantic and syntactic. When organized semantically phrasal verbs are grouped thematically in vocabulary sections entitled e.g. "Clothes", "Eating", "Drinking", "Driving", "Love \& friendship", etc. Although used in similar contexts not all of them are related to each other; thus students receive long lists

1. Associate Professor, PhD at Shumen University, Department of English Studies, Shumen, Bulgaria, e-mail: s.nedelcheva@shu.bg

2. The term verb-particle constructions is used interchangeably with phrasal verbs. 
of VP constructions to memorize. The syntactic organization chooses between syntactic elements and categorizes the constructions either by the verbs or by the particle. This method is closer to the cognitive approach but it does not point out the motivation of meaning. Therefore, both the semantic and the syntactic approach are unable to identify the actual motivation of meaning extension provided by the conceptual metaphor.

Applying the cognitive approach, this article attempts to exhibit the similarities and differences between verb-particle constructions of two synonymous verbs such as see and look. It aims at analyzing the nuances of meaning of the two verbs when combined with spatial particles and examines the image schemas associated with them.

\section{Theoretical background}

Verb-particle contractions, such as look after, look away, see around, see off, etc., also referred to as phrasal verbs or multi-word verbs, are a characteristic feature of the English language, particularly of spoken communication. Traditionally, English prepositions and particles have been considered largely as having arbitrary semantics. Dictionaries enlist numerous possible uses in different contexts without any apparent relation to one another. Learning them posits a problem for students who study English as a foreign language, who mostly see English VP constructions as idiomatic expressions which are random and unpredictable and must be learnt by heart without any systematic explanation of their uses. Celce-Murcia and Larsen-Freeman (1999) define phrasal verbs as "ubiquitous", while Walkova (2012) and White (2012) distinguish between literal (transparent) meanings (e.g., look around), completive meanings (e.g., see $o u t$ ) and idiomatic meanings (e.g., see off), which cannot be easily derived from the meanings of the verb and particle in the particular phrasal construction. In addition to their seemingly arbitrary nature VP constructions are also highly polysemous. This significantly increases their complexity and the number of meanings that learners should memorize.

A lot of research in Cognitive Linguistics has been dedicated to polysemy in general and more specifically to prepositions. Since Brugman's study (1981) on the meaning of over, much work has been done on prepositions from a cognitive perspective (Cuyckens \& Radden, 2002; Dirven, 1993; Lakoff, 1987; Radden, 1989; Taylor, 1993; Tyler \& Evans, 2003; Vandeloise, 1994). Their view that it is possible to find interrelations among the different senses of a preposition can be transferred to the various meanings of phrasal verbs and show them as motivated ones, and therefore opposes the idea that they are arbitrary (cf. Tyler \& Evans, $2003,2004)$. The different meanings of a polysemous word can be organized in a semantic network of related senses, some of them more central, others more peripheral. The basic meaning of a preposition is the spatial one, whereas the 
abstract senses originate from concrete senses "by means of generalization or specialization of meaning or by metonymic or metaphoric transfer" (Cuyckens \& Radden, 2002, p. xiii). More specifically English prepositions, or spatial particles as they are also called, encode an abstract conceptualization of a spatial configuration, based on a more specific spatial scene, what Tyler and Evans $(2003,2004)$ call the proto-scene.

Image schemas are highly schematic representations of force-dynamic and spatial relations and generally regarded in cognitive linguistics as central elements on the level of "preconception" (cf. Johnson, 1987; Lakoff \& Johnson 2002). Based on Lakoff's (1987, p. 459-461) and Johnson's (1987, p. 19-21) image-schema criteria, Hampe (2005, p. 1-2) extracts the following concise categorization of image schemas:

- Image schemas are directly meaningful ("experiential3"/ "embodied"), preconceptual structures, which arise from, or are grounded in, human recurrent bodily movements through space, perceptual interactions, and ways of manipulating objects.

- Image schemas are highly schematic gestalts which capture the structural contours of sensory-motor experience, integrating information from multiple modalities.

- Image schemas exist as continuous and analogue patterns beneath conscious awareness, prior to and independently of other concepts.

- As gestalts, image schemas are both internally structured, i.e., made up of very few related parts, and highly flexible. This flexibility becomes manifested in the numerous transformations they undergo in various experiential contexts, all of which are closely related to perceptual (gestalt) principles.

Image-schema identification was initially achieved via cross-linguistic analyses of spatial relations and motion concepts. The ensuing list is not exhaustive as it has never been a closed set:

a. BALANCE, CENTER-PERIPHERY, CONTAINMENT, PART-WHOLE, SOURCEPATH-GOAL

b. FORCE-DYNAMICS: ATTRACTION, BLOCKAGE, COUNTERFORCE, ENABLEMENT, REMOVAL, RESTRAINT (cf. Cienki, 1997, p. 3, 12; Johnson, 1987, p. 126; Lakoff, 1987, p. 267; Lakoff, Turner, 1989, p. 97-98)

a. CONTACT, SCALE, NEAR-FAR, SURFACE, FULL-EMPTY, PROCESS, CYCLE,

3. Grady (1999) notes that a consequence of the nature of interaction between humans and their environment is that certain kinds of experiences are frequently correlated. This correlation he calls "experiential correlation". 
ITERATION, MERGING, MATCHING, SPLITTING, OBJECT, COLLECTION (Johnson, 1987)

b. UP-DOWN, FRONT-BACK (Lakoff, 1987)

(3) a. INANIMATE MOTION, ANIMATE MOTION, SELF MOTION, CAUSED MOTION (Mandler, 1992, p. 593-596).

b. EXPANSION (Turner, 1991, p. 171), STRAIGHT (Cienki, p. 1998), RESISTANCE (Gibbs et al., 1994, p. 235), LEFT-RIGHT (Clausner, Croft, 1999, p. 15)

This study focuses on the image schemas applied to the phrasal verbs associated with two synonymous perceptual verbs, namely look and see. In Collins English Dictionary ${ }^{4}$, look is defined as follows: "If you look in a particular direction, you direct your eyes in that direction, especially so that you can see what is there or see what something is like." On the other hand, "When you see something, you notice it using your eyes" (ibid.). Therefore, when you look at something you can usually see it but you can see something without purposefully looking at it. The two verbs differ in their semantic component from the point of view of activity and experience. Activity is correlated with a process that is under the control of an actor/ perceiver (as in look at), experience is identified with a state that is not controlled (as in $s e e^{5}$ ), and consequently the subject is an experiencer ${ }^{6}$. From the image schema perspective the opposition may be associated with SELF MOTION VS. CAUSED MOTION. In this occasion, motion is conceptualized in a very broad sense and it does not necessarily involve movement as it is the case with vision.

This article focuses on the similarities and differences in the meanings of verb-particle constructions with see and look. We hypothesize that there are correspondences in the utilized image schemas and we aim at analyzing the nuances of meaning of the two verbs when combined with the same spatial particle. We mostly concentrate on the metaphorical meanings of the studied phrasal verbs and how they are systematically motivated in relation to the spatial ones.

All VP constructions with look and see were extracted from Longman Phrasal Verbs Dictionary (2000). In order to investigate the different uses of the phrasal verbs in naturally occurring data we used the Corpus of contemporary American

4 www.collinsdictionary.com/dictionary/english

5. For a detailed analysis of 'see' cf. Aneva, Ts. (2019). The semantic network of "see" (a corpus-based study).

6. According to Viberg (1984), there is a third group, source-based, which refers to constructions where the perceiver is not mentioned (e.g., Mary looks young). The last category, however, remains outside the scope of this study as it is not associated with spatial particles and does not form verb-particle constructions. 
English (COCA) ${ }^{7}$. The corpus is suitable for this kind of studies due to the variety of genres it contains: academic journals, fiction, media texts including spoken language from TV and radio programs. The second step of the analysis after excerpting all the phrasal verbs, involved identifying the central meanings of the VP constructions. We began by finding their etymological roots in the Online Etymology Dictionary ${ }^{8}$. If the original meaning was preserved and was currently in use we regarded it as the central meaning. Then we consulted Collins COBUILD Dictionary of Phrasal Verbs (2012) and Merriam-Webster Online Dictionary ${ }^{9}$ for potential extended meanings. Next all distinct meanings were analysed applying relevant image schemas. Finally, the conceptualizations of look and see VP constructions were compared revealing their motivation by the specific contributions of the verb meanings and the particle meanings.

\section{Data analysis}

After we extracted all the phrasal verbs with look and see from Longman Phrasal Verbs Dictionary (2000), we organized them in two parallel columns to show the correspondences of verb + particle constructions (see Table 1).

\begin{tabular}{|l|l|l|}
\hline Particle & LOOK + particle & SEE + particle \\
\hline after & Look after (1834) & - \\
\hline ahead & Look ahead (780) & - \\
\hline around & Look around (3733) & See around (270) \\
\hline at & Look at (119530) & - \\
\hline away & Look away (1211) & - \\
\hline back & Look back (6776) & - \\
\hline down & Look down (2456) & - \\
\hline for & Look for (18508) & - \\
\hline forward to & Look forward to (4232) & - \\
\hline in/ into & Look in (3153), into (3736) & See in (7282), into (516) \\
\hline off & - & See off (33) \\
\hline on & Look on (4015) & - \\
\hline out & Look out (4049) & See out (493) \\
\hline over & Look over (1629) & See over (436) \\
\hline through & Look through (1100) & See through (1426) \\
\hline to & Look to (5060) & See to (1554) \\
\hline up & Look up (13091) & - \\
\hline up to & Look up to (1008) & - \\
\hline
\end{tabular}

Table 1. Verb-particle constructions with look and see

7. https://www.english-corpora.org/coca/

8. www.etymonline.com

9. https://www.merriam-webster.com/dictionary 
Table 1 shows that look is much more productive in forming phrasal verbs. Seventeen look-VP constructions were attested, which are opposed to only seven see-VP constructions. The numbers in the brackets reveal their frequency based on more than 560 million words. The outlined tendency is that look-VP constructions outnumber those with see (except for see in and see through). The two parallel columns display that there are six instances of particle repetition, i.e. the same particle combines with both look and see. The most illustrative and memorable way of representing the meanings of the phrasal verbs is to compare and contrast them.

The most readily acquired are those referring to spatial configurations. The GOAL image schema is applied to look at vs. look away.

\section{Look at vs. look away}

Look at is associated with two main meanings:

$1 .=$ to examine/ study/ consider something carefully (e.g., One needs to continue to look at other empirical research before making a decision).

$2 .=$ to read something quickly and not in detail (e.g., We might be able to look at a film from 1932 and recognize at a glance that it was the product...).

The use of at began in 14c. and replaced on in the spatial contexts. At introduces the focus of the look without taking into consideration the relative sizes of the Trajector (TR) and Landmark (LM) ${ }^{10}$. When at took over the general spatial meaning, the uses of on in combination with look became more specialized. In the late 1500 s the meaning "watch as a spectator without getting involved" was introduced, e.g., Throngs of passersby looked on or stopped... A century later this use was extended to denote, besides "watch", also "regard in a certain way" (possible with upon, too), e.g., Women were sacred, looked on with great honor. The image schema of on shifted from the spatial suRfaCe to the more abstract GOAL.

Look at finds its antonym in look away because it denotes that the previous focus of attention is avoided (see 3.1.2).

look away = to turn your eyes away from someone or something that you were looking at.

Similarly to look at, look away is neutral to the characteristics of the reference object. The LM may be explicitly pointed out in the sentence, as from the hands in e.g. She couldn't look away from the hands, or it may be implicit if it has been mentioned previously in the context, e.g. Kendra finally forced herself

10. We use the term trajector (TR) for the more prominent, mobile participant in a (spatial) event, and landmark (LM) for the secondary, usually immobile and less salient participant. 
to look away. Both at and away refer to the GOAL schema but they may also be associated with the NEAR-FAR image schema due to additional elements in the contexts such as the adverbial from the hands above. If the LM of at is conceptualized as being NEAR, what is away is interpreted as FAR. Look when combined with either at or away is used unidiomatically.

Look ahead vs. look back

look ahead = to think about future events (e.g., And in that sense it's interesting to look ahead to this possible meeting in July between President Trump and President Putin).

look back $=$ to think about something that happened in past (e.g. I always look back at the original iPod ads that started in 2004).

Looking ahead has a literal meaning of looking in front of oneself. The corresponding image schema is that of a GOAL. Both look ahead and look back developed metaphorical meanings based on the cultural belief that future is in front of us, while past is behind. Many languages, English among them, express this conceptualization making use of spatial particles.

Look around vs. see around

look around $=$ to go to a place and look at what is there (e.g., I come to an abrupt halt and look around in disbelief).

To look around 'search about, look round' is from 1883, which makes it a comparatively recent development. The meaning of this phrasal verb is transparent as it is composed of the central meanings of the verb and the particle. It, however, presupposes at least two activities. On the one hand, the doer visits a place and, on the other hand, s/he looks at the things in it. The SELF MOTION image schema is involved in the activity combined with a circular movement.

see around = to visit a place and go around looking at it (e.g., Then he whistled and the lights came on, dim but enough to see around).

This use of see around is very infrequent as mostly the synonymous look around is used in this context. The number of examples shown in Table 1 does not correspond to this particular meaning. It encompasses also the literal meaning of see around, which is the one exploited predominantly. The difference in the semantics of look around and see around is found in the variation of actor/ experiencer corresponding respectively to the role of the person looking or seeing.

Look up (to) vs. look down (on)

The spatial, literal meanings of the two VP constructions originate in $13 \mathrm{c}$. Their metaphorical extensions are attested much later: look up to 'regard with respect and veneration' is from 1719. To look down on in the figurative sense 'regard as 
beneath one' is from 1711; to look down one's nose is from 1921. All metaphorical extensions rely on the conceptual metaphor UP IS GOOD, DOWN IS BAD (Lakoff, Johnson, 1980). Those that are looked up to are good, honorable and deserve admiration, e.g., Somehow I become the sort of man that other men look up to. Those that are looked down on are considered of bad quality, disagreeable and inferior, e.g., They're also incredible snobs, so they look down on Donald Trump even though he's rich...

The motivation of looking something $u p$ as information in a reference book (dictionary) or online database is not discussed in the linguistic sources. The meaning was first attested in 1690s and no clear evidence is preserved about the semantic relation of the figurative expression to the literal meaning of look up. There are two hypotheses:

a. According to $\mathrm{MED}^{11}$, in ME loken up was a synonym for loken in = to $\mathrm{read} /$ to consult a text (to look into a book).

b. The spatial particle up emphasizes the process of opening up the book.

Both of them have the potential to give rise to the metaphorical meaning.

Look after (someone or something)

$1 .=$ to take care of (e.g., She was not expected to look after her brother and sister).

2. = to make sure that someone/ something is safe and well (e.g., Doc trusted me to look after things while he's gone).

The earliest attested meaning of look after is 'to look toward' (c. 1200), which is purely spatially oriented and motivated by the GOAL image schema because when your look is directed after someone or something you show that you think about them. A century later look after came to mean 'take care of' which shows how thinking a lot about someone/ something is experientially correlated to caring about them. The second meaning can be interpreted as a metaphorical extension of the first one considering that when you take care of someone/ something you are cautious and try to keep them safe.

Look for (someone or something)

In $16 \mathrm{c}$. look for was attested with two conceptually related meanings identified with the GOAL schema:

1. = to search for something or someone, e.g., We had to look for a house with a dining room big enough for two tables.

2. = to expect, anticipate, e.g., But don't look for a major surge in U.S. nuclear

11. https:/quod.lib.umich.edu/m/middle-english-dictionary/dictionary/MED25944 
power anytime soon.

The 'search' meaning of look for could be interpreted as literal as it transparently combines the meanings of the two constituents of the VP construction: when a person tries to find an object $\mathrm{s} / \mathrm{he}$ directs one's eyes towards it. The 'expect, anticipate' meaning is experientially correlated with thinking about a particular event, which is metaphorically associated with looking for it in the future. Further extension of this meaning is expressed by look forward to.

Look forward to $=$ to wait or hope for, especially with pleasure, e.g. I look forward to working together with the SIE team

The meaning of the idiomatic expression is motivated by the spatial senses of look and forward 'in the direction being faced'. When one longs for and dreams for something $\mathrm{s} / \mathrm{he}$ looks at it. The literal meanings of look ahead and look forward are synonymous as they denote looking in the same direction, the direction one's face is turned to. They have developed different metaphorical meanings but both are focused on the future, in correspondence to the conceptual metaphor FUTURE IS IN FRONT OF US and the GOAL image schema.

Look in(to) vs. see in(to)

3.8.1. Look in(to), generally, is a transitive VP construction followed by an inanimate direct object:

$1 .=$ to find out more about something in order to improve the situation, e.g., When you get a role, you like to look in yourself for what's there of that character, maybe your friends.

2. = to investigate or examine, e.g., Bendixen and Kennair want to look into this in an upcoming study.

The two meanings are closely interrelated in the sense that when you try to find more about something, you actually analyze and explore it. However, when the activity refers to a physical object the spatial meaning of the verb is applied, e.g., "Did you look in her room before you came downstairs?" In both spatial and metaphorical cases, though, the image schema of CONTAINMENT is used.

3.8.2. See in(to) is also governed by the Containment schema, e.g., With the sun at his back he could see into Cheryl's car. When look in(to) and see in(to) are used intransitively in their literal senses the difference in their meanings lies only in the difference between look and see. Unlike look in, see in can be used transitively with animate objects, which extends its spatial meaning:

1. = to show a visitor the way to enter a building, office, etc. by walking there with them, e.g., I'll see you in.

Further on, the spatial schema has been spread in the metaphorical domain, where the landmark is a human body interpreted as a container: 
2. = to notice a particular quality in someone or something that makes you like them, e.g., I write your experience, see into you all that is cliché: desire, fear, hope.

or an abstract domain conceptualized as three-dimensional, e.g., She read that a shiny surface helped psychics and mediums see into the future or the past, hence crystal balls.

In the CONTAINMENT schema in and out are in opposition. Corresponding oppositions exist between VP constructions, e.g. those with look and see.

Look out vs. see out

The spatial use of look out, which is based on the CONTAINMENT schema, e.g., Look out your window, is an antonym of look in, e.g., Then I happened to look in the mirror. Both LMs, your window and the mirror, are conceptualized as containers. In addition, look out is also used as a warning to avoid imminent danger:

look out = to be careful, e.g., "Look out", someone shrieked. "He's gonna hit the board-walk!"

This metaphorical extension may be explained if we conceptualize the focus of attention as a container. The imperative Look out! makes the addressees turn their eyes in a direction which is outside their previous field of vision. From this perspective the metaphorical look out is semantically correlated to the spatial look out.

Unlike look out, which is used intransitively, see out is a transitive verb with both animate and inanimate objects. Spatially, its meaning is transparent, deriving from the meanings of the constituents, e.g., When you came out of the grocery store, did you see him out on the street? Metaphorically, the VP construction has acquired a meaning opposite to the idiomatic meaning of see s.o. in:

see someone out $=$ to accompany a visitor showing him/her the way out, e.g., We can see him out; he brought his own car.

In addition, another metaphorical extension, related to the CONTAINMENT schema, is attested:

see something out $=$ to be involved with a task or project until it is completed, e.g., I just want to see it out as soon as possible.

This use of out corresponds to the Completion Sense, mentioned by Tyler and Evans (2003, p. 204). Its motivation is in the correlation between the TR leaving a bounded LM, and the process of leaving being complete. Through pragmatic strengthening the completion associated with such spatial scenes has been 
conventionalized, giving rise to a distinct Completion Sense associated with out.

Look over vs. see over

Although look and see are cognate and they are combined with the same spatial particle over, the metaphorical extensions of the two VP constructions have developed following different motivation. The meaning of look over "scrutinize" dates back to mid-15c. Since then its meaning has been slightly changed so nowadays it denotes:

look over $=$ to make a quick examination of something", e.g., You should ask several peer reviewers to look over those documents that you plan on sending to employers.

The Examination sense which is associated with over (cf. Tyler, Evans 2003) refers to a spatial scene where the TR and consequently TR's line of vision is directed at the LM. By experiential correlation, when examining, the viewer is located above the LM and in proximity to the LM. However, if the examined object is a place the SURFACE image schema is also involved, e.g., Customers look over suits costing eighteen hundred to twenty-three hundred yuan. Despite that the same spatial configuration applies to the phrasal verb see over, an additional image schema is drawn in, that of SELF MOTION:

see over = to make a tour and examine (a building or site), e.g., Bridget asked if he'd like to see over the house.

The TR moves to the place first and then examines it, so elements of the image schema NEAR-FAR also participate in the scene as the TR changes its position from being distal from the LM initially to being proximal the LM in order to complete the task.

\section{Look through vs. see through}

No correspondence is found between the meanings of look through and see through even though they share the same spatial particle.

look through $=$ to read something, usually quickly and not very carefully, e.g., I set my cup on the coffee table and look through the magazines.

see through = not to be deceived by; detect the true nature of, e.g., They would be able to see through me.

The literal meaning of through 'in and out again' is the ground for both VP constructions but their idiomatic meanings have been developed via different metaphors. With look through, the TR deals with a physical LM, e.g., a pile of paper. The image schema of PATH is evoked. Although a PATH is usually associated with motion, looking presupposes no change of location. A 
metaphorical PATH, relates a starting point/ a source with an end point/ a goal, all the contiguous points in between form the path. In 3.11.1., going through the magazines is regarded as following a path, starting with the first one and ending with the last one.

With see through, the LM is a human being, more specifically what s/he says, which makes it an abstract notion. Therefore, seeing through is not so much related to the ability of beholding but to the conceptual metaphor SEEING Is UNDERSTANDING.

Additionally, unlike look through which is used intransitively, see through has also built up transitive metaphorical extensions:

1. see someone through = to support a person in a difficult time, e.g., We had very little supplies to see us through.

2. see something through $=$ to persist with a project or task until it is completed, e.g., Like his father, he had the vision and the nerve to undertake the unusual and see it through.

The two meanings rely on different conceptual metaphors. When the LM is a human being, the TR refers to a particular period of time that is implicit in the sentence. The conceptualization is based on the metaphor TIME IS SPACE. When the LM is inanimate, the VP construction acquires the Completion sense. It is very often that we speak of situations as being physical places where we can go in, out or around. Through entails leaving a place after having entered it, therefore it is experientially related to something being finished. The meaning of completion results from interpreting the physical location of the TR as a process. In this explanation, the Completion sense is not describing a purely spatial relation.

Look to vs. see to

The two VP constructions have developed quite different metaphorical meanings.

Look to has two meanings:

1. = to pay attention to, take care of, e.g., McPherson will look to build on his success with Top Tier this summer.

2. = to anticipate or expect, e.g., We are going to look to add some players that are talented.

Both of them were developed quite early, $14 \mathrm{c}$. and $17 \mathrm{c}$. respectively, and both of them rely on the GOAL image schema. Each one of them expresses a relation in which the TR is oriented towards an accentuated LM. The spatial scenes associated with to often prompt the inference of motion of the TR in the direction 
to the LM. However, with a verb such as look there is no path - in the sense of contiguous locations between a starting point and an end point - explicitly coded by to. The two idiomatic meanings seem conceptually related. On the one hand, paying attention to something presupposes a focus of attention, a highlighted LM, a GOAL. On the other hand, when we expect something and wish for it to happen, it is not only our focus of attention, but a GOAL that we try to achieve.

See to $=$ to deal with something, make sure it happens, e.g. If you would be so kind, see to my bags.

Look to in its 'take care of' sense is similar in meaning to see to but they are not interchangeable due to their structural features. When used idiomatically see to is followed by a noun phrase, while look to in this particular sense precedes another verb, which designates the activity that should be attended to.

See off

1. = to accompany a person who is leaving to their point of departure, e.g. On Friday, she'll help see off President Obama as he flies away from Washington.

$2 .=$ to repel an invader or intruder, e.g., I want you personally to see them off the mountain and back to their barracks.

The two meanings of see off are interrelated as the result of both of them is a person leaving his/ her initial place and going to another one that may not be mentioned in the sentence. As a spatial preposition, off denotes 'not in contact with', but there are contexts which do not imply a contact but underline the fact of separation. Therefore, the two meanings are governed not by the CONTACT schema but by the opposite SEPARATION image schema. A more detailed analysis shows that apart from the common SEPARATION schema of the two meanings, another pair of schemas differentiates them. Accompanying someone is associated with a SELF MOTION, while repelling a person leads to CAUSED MOTION.

\section{Conclusions}

The analysis in this study shows that VP constructions with look and see are governed by a number of image schemas: SOURCE-PATH-GOAL, SURFACE, NEARFAR, UP-DOWN, CONTAINMENT, SEPARATION, SELF MOTION, CAUSED MOTION, etc. The most interesting cases in the research are the phrasal verbs that share the same spatial particle. The present research reveals that they have developed distinct meanings and there is no interchangeability among them, except for look/ see around. The difference in the meanings of look around/see around lies in the opposition between the semantic roles of the performer of the activity, whether $\mathrm{s} / \mathrm{he}$ is an actor paired with the verb to look, or an experiencer combined with the verb to see. The other image schemas are exemplified in Table 2. 


\begin{tabular}{|c|c|c|c|}
\hline PATH-GOAL & CONTAINMENT & SURFACE & COMPLETION \\
\hline $\begin{array}{l}\text { Look around 'walking } \\
\text { around a place and looking' }\end{array}$ & $\begin{array}{l}\text { Look in, into } \\
\text { 'investigate' }\end{array}$ & $\begin{array}{l}\text { Look over } \\
\text { 'examine } \\
\text { quickly' }\end{array}$ & $\begin{array}{l}\text { See out } \\
\text { 'complete a } \\
\text { task' }\end{array}$ \\
\hline $\begin{array}{l}\text { See around 'visiting a place } \\
\text { and looking at it' }\end{array}$ & $\begin{array}{l}\text { See in, into 'show a } \\
\text { person in' }\end{array}$ & $\begin{array}{l}\text { See over } \\
\text { 'visit and } \\
\text { examine' }\end{array}$ & $\begin{array}{l}\text { See sth } \\
\text { through 'to } \\
\text { persist until } \\
\text { the task is } \\
\text { completed' }\end{array}$ \\
\hline $\begin{array}{l}\text { Look over 'examine } \\
\text { quickly' }\end{array}$ & $\begin{array}{l}\text { Look out 'watch } \\
\text { out' }\end{array}$ & & \\
\hline $\begin{array}{l}\text { See over 'visit and } \\
\text { examine' }\end{array}$ & $\begin{array}{l}\text { See out'accompany } \\
\text { a person }\end{array}$ & & \\
\hline \multicolumn{4}{|l|}{ Look through 'read quickly' } \\
\hline \multicolumn{4}{|l|}{$\begin{array}{l}\text { See through 'understand the } \\
\text { truth' }\end{array}$} \\
\hline \multicolumn{4}{|l|}{ Look to 'anticipate' } \\
\hline See to 'deal with' & & & \\
\hline
\end{tabular}

Table 2. Image schemas of verb-particle constructions with look and see The data in Table 2 proves the hypothesis that there are correspondences in the applied image schemas. The analyzed phrasal verbs differ in their meanings due to different conceptual metaphors that took part in their development, e.g., UP Is GOOD, DOWN IS BAD in look up to and look down on; FUTURE IS IN FRONT OF US in look ahead and look back; TIME IS SPACE in see through, etc.

This research gives additional evidence that cognitive linguistics approach can present the meanings of phrasal verbs as systematically motivated. To implement this approach in learning VP constructions, teachers may choose a couple of frequently used phrasal verbs close in their meanings and ask students to compare and contrast them. By giving the learners the motivation behind these phrasal verbs, teachers will allow them to understand the correlations existing between literal and idiomatic meanings, which will help students in their future encounters with multi-word verbs. Language instructors may also provide corpora examples to illustrate how these phrasal verbs are used in naturally occurring language and help foreign learners master their idiomatic meanings in situational context. 


\section{References:}

Aneva, Ts. (2019). The semantic network of "see" (a corpus-based study). Studies in Linguistics, Culture and FLT. Vol. 7. Sofia: Asenevtsi, 22-35.

Cienki, A. (1997). Some properties and groupings of image schemas. In M. Verspoor, K. D. Lee, \& E. Sweetser (Eds.), Lexical and syntactical constructions and the construction of meaning (pp. 3-15). Amsterdam/Philadelphia: John Benjamins.

Clausner, T., \& Croft, W. (1999). Domains and image schemas. Cognitive Linguistics, 10, 1-31.

COBUILD Dictionary of Phrasal Verbs. (2012). Glasgow: Harper Collins Publishers.

Gibbs, R. W., Jr., \& Berg, E. A. (2002). Mental imagery and embodied activity. Journal of Mental Imagery, 26, 1-30.

Gibbs, R. W., Jr., \& Colston, H. L. (1995). The cognitive psychological reality of image schemas and their transformations. Cognitive Linguistics 6: 347-378.

Gibbs, R. W., Jr., Beitel, D. A., Harrington, M., \& Sanders, P. E. (1994). Taking a stand on the meanings of stand: Bodily experience as motivation for polysemy. Journal of Semantics, 11, 231-251.

Grady, J. (1999). Heaviness and difficulty: "Image content" vs. "response content" in conceptual metaphors. Talk at the 6th International Cognitive Linguistic Conference (Stockholm, July 1999).

Johnson, M. (1987). The body in the mind. The bodily basis of meaning, imagination, and reason. Chicago: Chicago University Press.

Lakoff, G. (1987). Women, fire and dangerous things. What categories reveal about the mind. Chicago: The University of Chicago Press.

Lakoff, G., \& Johnson, M. (1999). Philosophy in the flesh. The embodied mind and its challenge to western thought. New York: Basic Books.

Lakoff, G., \& Johnson, M. (2002). Why cognitive linguistics requires embodied realism. Cognitive Linguistics, 13, 245-263.

Lakoff, G., \& Turner, M. (1989). More than cool reason. A field guide to poetic metaphor. Chicago: The University of Chicago Press.

Longman Phrasal Verbs Dictionary (2000). Harlow: Pearson Education Limited.

Mandler, J. M. (1992). How to build a baby: II. Conceptual Primitives. Psychological Review, 99, 587-604.

Turner, M. (1991). Reading minds. The study of English in the age of cognitive sciences. Princeton, NJ: Princeton University Press.

Tyler, A., \& Evans, V. (2003). The semantics of English prepositions: Spatial scenes, embodied meaning and cognition. Cambridge: Cambridge University Press.

Tyler, A., \& Evans, V. (2004). Rethinking English 'prepositions of movement'. Adpositions of Movement, 247-270. Amsterdam: John Benjamins.

Viberg, A. (1984). The verbs of perception: a typological study. In B. Butterworth, B. Comrie, \& Ö. Dahl (Eds.) Explanations for language universals, (pp. 123-162). Berlin: Mouton. 